\title{
A Study of THe Experiences of
}

\section{INTEGRATION AND Settlement of Afghan Government-Assisted Refugees in Halifax, Canada}

\author{
Shiva Nourpanah
}

\begin{abstract}
This article presents a qualitative study of the experiences of a sample of Afghan refugees who have settled in Canada. Using Anthony Giddens's concepts of structure and agency, the author analyzes interview data to explore how the respondents express their agency within the structural constraints of refugee life. In light of the research findings, it is argued that Afghan refugees form a diverse and heterogeneous population, in stark contrast to the essentialized and homogenous portrayals of silent, suffering victims of circumstance as found in popular media and policy discourse.
\end{abstract}

\section{Résumé}

Cet article présente une étude qualitative des expériences d'un échantillon de réfugiés afghans qui se sont installés au Canada. En utilisant les concepts de structure et d'agentivité d'Anthony Giddens, l'auteur analyse les données de l'entrevue afin d'explorer la façon dont les répondants expriment leur entremise dans les contraintes structurelles de la vie de réfugié. À la lumière des résultats de la recherche, on soutient que les réfugiés afghans forment une population diverse et hétérogène, en contraste avec les représentations essentialisées et homogènes d'eux comme muettes et soumises victimes des circonstances que l'on trouve dans les médias populaires et le discours politique.

\section{Introduction}

Government-assisted refugees (GARs) are refugees who have been recognized by the United Nations' High Commissioner for Refugees (UNHCR) to meet the definition of refugee as set out in the 1951 Convention on the Status of Refugees, and referred to a third country, such as Canada, for resettlement. After further screening by the immigration officials of the third country, these people are issued documentation allowing them to leave their country of asylum and enter the resettlement country as legal residents of that country. Upon arrival in the country of resettlement, they are met by state-funded service providers who provide them with a range of services designed to ease their settlement in their new country. Thus, Afghan GARs arrive in Canada as landed immigrants, they become permanent residents shortly after arrival, and, like any permanent residents who have migrated to Canada through other channels, may apply for and receive Canadian citizenship within the foreseeable future.

Afghan refugees have typically lived in other countries of asylum neighbouring their home country of Afghanistan for several years before their entry to Canada. ${ }^{1}$ Iran and Pakistan remain the world's largest hosts to Afghan refugees, neither of which offer stable and secure legal and physical protection systems for the refuge population within their borders. $^{2}$ From a socio-cultural standpoint, Afghans share the same religion and language as the citizens of these host societies, and many are able to integrate within the labour 
market, albeit within the black market, and with no access to labour rights. ${ }^{3}$

The research question and fieldwork for this article arose out of a curiosity to study the settlement experiences of Afghan GARs in Halifax, a mid-sized city on the east coast of Canada, which does not have a sizeable immigration or diverse population such as found in larger Canadian cities. Halifax is the largest urban centre east of Quebec, part of the region known as Atlantic Canada, comprising four provinces with a problematic and thorny history of welcoming newcomers in their midst. ${ }^{4}$ This research was undertaken to develop an understanding of the integration and settlement process of Afghan GARs living in this city, and the cultural and social challenges of their new society, intending to generate new knowledge of the effects of resettlement in the lives of refugees. Utilizing the concepts of agency and structure as pertaining to the experience of refuge and subsequent settlement, I ask, from a social and cultural standpoint, how Afghan government-assisted refugees adapt to life in Canada, where the culture, values, and lifestyle of the dominant majority are very different from that of their country of origin and the country of first asylum. This study explores the answers to these questions based on 10 in-depth, qualitative interviews with Afghan GARs in Nova Scotia.

There is extensive scholarly literature critiquing the politically silenced and deliberately muted construct of "refugees," examples of which can be found in the writings of Hannah Arendt, ${ }^{5}$ Liisa Malkki, ${ }^{6}$ Julie Kristeva, ${ }^{7}$ and Peter Nyers. ${ }^{8}$ These authors vehemently criticise the popular image of refugees as victims and passive sufferers who lack agency. Do Afghan GARs conform to this image, and to what extent are they active agents, able to make valid and significant choices in shaping their new lives?

The theoretical concepts of structure and agency expounded by Anthony Giddens provided the framework for thinking about these issues and bringing together the political (individual, agentic) and the sociological (structural, societal). ${ }^{9}$ Giddens provided the tools for examining the interaction of the individual within the social fabric, and the theoretical grounding for the "encountering" and "routinization" that form the basis for this fabric. The interview questions were developed in an effort to concretize how the encountering and routinization takes place in the lives of Afghan refugees in Halifax. How do they spend their days? Whom do they see? What are their current social and cultural practices, and what are their individual interpretations of the received practices, assumed to be uniform for all "Afghans" and, indeed, for all Muslims? ${ }^{10}$

\section{Literature Review}

The settlement of immigrant groups in host countries, especially in a country such as Canada, which has not only been "built" on immigration but where there continues to be an active immigration policy, has aroused scholarly and policy interest. A frequently cited definition of integration, positing it as an objective to be achieved, is: “

Key domains of integration are related to four overall themes: achievement and access across the sectors of employment, housing, education and health; assumptions and practice regarding citizenship and rights; processes of social connection within and between groups within the community; and structural barriers to such connection related to language, culture and the local environment."11

Yet the issues surrounding the integration and settlement of refugees remain largely divergent from this mainstream literature on "integration" and its achievement by immigrants. In reviewing literature on refugee integration, the scholarly interest in mental health issues as refugees settle into new societies jumps to the forefront.

Nann provides a detailed argument about how the "culture shock" resulting from resettlement exacerbates the stressful and precarious situation of refugees resettled from various countries to North America, and how forced migration "involves high risks to the mental health of those people [who have experienced it]"12: “

When migrants resettle into a new environment, they are usually exposed to a different culture, different ways of living and perhaps, to various forms of discrimination and prejudice. Previous research of migration populations has shown that homesickness often persists along with an obdurate clinging to the past, thereby prohibiting successful adaptation to the present. Among people who have been oppressed in their home country, a lingering fear of persecution may continue long after migration."13

While Lipson and Mileis concur that "migration is a stressful experience requiring accommodation, adaptation or coping," consequently classifying migrants and refugees amongst vulnerable populations, ${ }^{14}$ they take issue with what they consider to be the two dominant paradigms in the literature on refugees and health: the first views refugees as "a poverty-stricken and political class of excess people," and the second objectifies refugees as medical phenomena. The authors present a critical feminist view of refugees, which instead of concentrating on health and illness, views refugees as resilient, stating that "refugees provide a vivid example of the human capacity to survive despite the greatest losses and assaults on human identity and dignity."15

Witmer and Culvert ${ }^{16}$ also critically review the literature available on refugee mental health, specifically the "trauma" and resilience" of Bosnian Muslim families. They argue 
that the available research is focused on the "post-traumatic stress disorder, psychopathology, and individual-based assessment and intervention, with few studies addressing concepts of adaptation, functioning or resiliency, and even fewer focusing on the family as a unit." 17

In a study of the role of leisure pursuits in the adaptation of Afghan immigrants and refugees in Winnipeg, the authors' point of departure is that "globally, Afghan immigrants/ refugees are a marginalised minority group who encounter substantial hardships and stress in the processes of adaptation to a new environment." 18 The hardships and trauma experienced by these refugees explain the complexity of negotiating identity and prejudice (in this case, anti-Afghan prejudice) in the modern era of international wars, interethnic conflict, and mass migration across the globe. ${ }^{19}$

Katrin Eun-Myo Park points out the gendered nature of mental health afflictions: "One of the most pressing issues facing Afghan refugees, especially women, today is their mental health, according to the World health organization (WHO) and advocates for women. Although the issue of survival takes priority, more people are recognizing the importance of the mental health of refugees ... Noting that over 2 million Afghans are estimated to suffer from mental health problems, WHO urged the reestablishment of mental health services to treat them." 20

Parin Dossa resists these tropes of mental problems in her work on Iranian immigrants. She argues that these labels hark back to the political silencing and problematizing of refugees, which was touched upon above. Referring to a dominant world order that defines the practices of multiple nation-states, she writes, “

Displaced people are as seen challenging and subverting this order, and this is why national and international bodies control and manage anyone who is perceived not to have territorial roots. A common strategy is to use the idiom of mental health as exemplified in constructs such as 'refugee mental health' and 'post-traumatic stress disorder."'21

The works of Evangelia Tastsoglou on the settlement experiences of immigrant women in the Maritime provinces of Canada, ${ }^{22}$ and Parin Dossa ${ }^{23}$ on those of Afghan women, were particularly relevant, as many of their themes were identified in the findings of this research. Themes such as food, parenting, friendships and social networks, education, and religion were covered, with the consistent underlying motif of how to be or to remain "Afghan" while developing a sense of belonging in Canada. These will be discussed at greater length in the research findings.

\section{Methodology: Qualitative Research, Access, and Recruitment}

I conducted 10 open-ended, in-depth interviews, all with Afghan government-assisted refugees who were resettled in Canada via UNHCR within the past five years. These interviews were conducted from October 2009 to February 2010. Nine of them took place in a family setting, with the children (often young adults) and both parents present and answering the questions collectively. One interview took place with an individual (male). All took place at the homes of the interviewees, with prior appointment. I undertook one additional interview with an Iranian woman contracted by the government and NGOs to provide translation services to Farsi-speaking immigrants in Halifax, for the purpose of triangulation and validation of my data. The interviews for this study were all conducted and transcribed in Farsi, the language commonly spoken by both Afghanis and Iranians, with the quotes used in this study translated to English by the author. Pseudonyms are used throughout the study, to ensure anonymity and confidentiality.

The chosen research methodology, that of qualitative research, is particularly apposite in studies on immigrants, for it provides a counterpoint to the prevalent discourse on the homogenization of immigrants, touched upon above, in which immigrants from a particular country or of a particular religion are assumed to have a "common personal history" and "a sameness of experience in Canada." ${ }^{24}$ But "qualitative research reveals that this is decidedly not the case; immigrants (regardless of their visa status) have distinctive personal histories and are as socially, economically, and politically differentiated as more longstanding Canadians." 25

And if qualitative research is well-suited to documenting the experiences of immigrants, for refugees in particular it can be very apt, for it has the potential to provide space for the "voices" of the refugees while critically situating the researcher in relation to the research subjects. As discussed above, refugees are typically lacking in political and legal voice. Their movements and access is heavily controlled by administrative structures with no space for critical reflexivity, and they are subject to a homogenizing discourse in both popular and academic media that emphasizes their victimhood and silent suffering. In this environment, then, “refugees' perceptions and knowledge of their problems are designated as subjective, biased and uninformed. They are even ultimately viewed as misleading because institutions interested in absorbing or rehabilitating refugees impose their own definitions of relevant facts, needs and goals in a way that the institute can 'handle them"' ${ }^{26}$

Harrell-Bond and Voutira detail the almost surreal bureaucratic and administrative obstacles in gaining 
"access" to refugees, whom they call "invisible actors," placed in their way by UNHCR and government authorities: "

It is the problematique of studying these refugees which was the main stimulus for writing this paper, but our concerns with the general problems of accessing refugees for research purposes and disseminating the findings led us to include a more general discussion of the challenges raised in the context of accessing the 'refugee' as a persona, as a person, and as a public perception, within spaces that are visible and identifiable, but largely inaccessible to researchers for a variety of reasons." 27

Yet while the GARs live in Halifax openly, ostensibly free from institutional control, accessing and recruiting participants for my study proved one of the most challenging phases of my study. And once I gained some access, negotiating the (often unspoken) terms on which the interviews were carried out, and establishing rapport with the participants proved to be equally onerous. As I wasn't researching a "community" as such, rather a diffuse set of households, with very heterogeneous and diverse lifestyles (indeed, one of the main goals of this study was to document the sheer diversity of outlook and backgrounds of "Afghan refugees", ranging from atheist to extremely religious, urban to rural, and educated to non-literate, and so on), I didn't have to deal with any "gatekeeper" or "professional stranger-handler," 28 but neither could I rely on one point of entry or the much-relied-on "snow-balling sampling" method. "Do you think you can introduce me to your friends and acquaintances, so I can interview them, similar to what we had now?" I recall asking Hussein, a male research participant, after our interview. "No, I am sorry, I cannot do that. Of course now I know you, so I didn't mind being interviewed, but others do not know you, and if, God forbid, anything unpleasant should arise from these interviews, I don't want to bear the responsibility." This was a fairly typical attitude. Public notices and requests to the local settlement NGO to pass my information to GARs proved fruitless, and at times it seemed to me each family were their own gatekeeper, in terms of their sheer (understandable) reluctance to allow a stranger in their midst to be questioned. The fact that, as refugees, they demonstrated great caution needs hardly belabouring. My breakthrough points came on two occasions: once, when I attended the Quran lessons in a local mosque, with my hair and body covered in full hijab, contrary to my general mode of dress in Canada. There, I became friendly with a pair of young Afghan sisters, who then introduced me to their father and secured an invitation for me to a large family gathering. The second occasion was at a large multicultural potluck event organized by a local NGO, where I showed up with my own family in tow, my hair and body once more wrapped in full hijab, covered with the same types of clothing I have to wear in Iran. My husband persuaded some Afghan men to let me interview them; I talked to the women, and I had five interviews lined up that evening.

Although I appreciate that "the goal of establishing true rapport requires honesty of the researcher," 29 I felt rather dishonest showing up for those interviews while continuing to wear the hijab, but they had first seen me in full hijab, and I would have felt foolish and unwelcome if I had gone bare-headed. I strategically took my little daughter with me, to cement my position as a friendly, non-threatening, motherly, harmless figure, and a box of cookies, and the interviews were like long familial gatherings, where we were courteously welcomed in, settled in the living room, offered tea and sweets and nuts, and then simply chatted for hours, albeit a chat in which I tried to follow a structure of prepared questions.

Sylvain ${ }^{30}$ documents the challenges of doing fieldwork in a hostile environment, where the dominant world view is totally against what she believes in. Although in no sense was the disparity in the world view between myself and my more religious participants of the same degree as that encountered by Sylvain in the racially segregated farms of the Kalahari, I experienced some inner unease in presenting myself as an observant Muslim woman to the families that I perceived to be religious. As an Iranian woman, however, I am totally accustomed to adjusting my veils and clothing in accordance with the surroundings, and soon I digested the difficulty.

As a former UNHCR professional, I also found my position problematic. I had to be clear that first, this did not mean that they were under any form of obligation to have an interview with me, and second, agreeing to be interviewed did not mean that I could use my past connection to influence the resettlement process of their relatives back in Iran. Here, I opted for complete honesty: clarifying that I used to work for UNHCR but that I no longer did (in fact, I had been a caseworker for at least one of the families who recognized me from several years ago in Iran) and that I had no intention, at that juncture, to return to my former line of work. Nobody displayed discomfort at these disclosures, and indeed, my participants were generally fairly adept at turning the tables on me, asking me at least as many questions as I asked them, not just on what I study and why, but also why I left Iran, what I do for child care, how I pay my tuition fees, how far my husband supports me in my quest for higher education, whether my parents will visit Canada, whether I intend to return to Iran, and so on.

Young meditates on the positionality of the researcher and the researched, acknowledging the "deeply unequal political structures" 31 that create the fissure between them. 
"The possibility of resolving the very real social and cultural disparities that create the gap between the self and the otherthe key antimony at the heart of our discipline - through a transcendent philosophical maneuver seems dishonest to me." 32 That is, she does not want to pretend to some form of revolutionary politics in order to claim solidarity with her research subjects, nor can she assume she can somehow overcome her own social positioning and subjectivity. I, too, acknowledge our disparities and the inequalities produced by social and historical processes and do not pretend that they can be transcended in the course of an afternoon chat. To develop that sympathetic, charitable understanding, verstehen, the empathetic interpretation of the "Other" is not to cease thinking of oneself, but to recognize that the "Other" is not as distant, as strange as one would think, or as bureaucracies, agencies, and media would portray.

\section{Research Findings}

How Not to Forget: The Culture of Being Afghan

As I walked into the homes of the research participants, I was struck immediately by how culturally specific or "Afghanized" the surroundings were, with many traditionally Afghan furnishings and decorations: embroidered wall-hangings, sofa covers, framed calligraphy, and pictures of Afghanistan were in abundance. Of the women participants, Razieh, Sara, Meigol, Maryam, and Nasrin were veiled in traditional provincial styles, with flowered chadors-long thin sections of cloth covering the head and falling to the ground, held in place by the hands or wrapped and tied around the body. Zahra was dressed with an Iranian city-style head scarf and fashionable black manteau-a knee-length thin coat that has replaced the chador in the cities of Iran, often in tailored and figurehugging styles, much decorated and embellished. Sabrina and Maliha were dressed in casual Western clothing, with no veils. Even in this small sample of women, one comes across striking differences in dress, and given the highly politicized and ongoing debate about women's clothing in religious and non-religious contexts, these differences are meaningful, indicating not just personal preferences but expressing a range of religious and political beliefs and backgrounds.

Despite the long absence from their native country, then, the identity of the research participants was firmly established as "Afghans" with plenty of visual cues even before the discussions started.

\section{Cultural Experiments: Families, Friends, and Schools}

Every so often, a horrible tale of "honour killings" spills out in the media with details of daughters of Middle Eastern or South Asian families being abused, imprisoned, and killed by their fathers, brothers, and even mothers for having boyfriends, or refusing to marry in accordance to family arrangements. "Honour Killings' on the Rise in Canada" warns one such headline, ${ }^{33}$ listing a gruesome series of such events perpetuated in Muslim families. These events and their construction in the media give an added urgency to the possibility of cultural conflicts in the family site, and it was of particular interest to see how Afghan parents handled the exposure of their children to Canadian culture and society.

One father remained silent on the question regarding his children's hypothetical refusal to follow their religious norms. In all the other families, the parents declared themselves willing to accept the choices of their children. Hussein and Zahra, a husband and wife who were both observant Shiite Moslems, agreed that they cannot force religion on their children: "I would not force them. We do not force our religion on anybody, though of course we would encourage them. You can see for yourself-she [their eldest daughter] is nine years old now but does not cover her hair. For us, morality is important, whether someone is good does not depend on their religion."

Indeed, their daughters receive swimming lessons at the local YMCA, which can be viewed as the sort of "cultural experimentation" referred to above. A Shiite family allowing their girls to swim is a phenomenon that would rarely be seen in their home country and is an instance of the individual modifications and adaptations of received cultural and traditional norms.

Maliha also seems willing to let go of traditions. She talks of marriage and how she sees Afghan marriage, "which is for life," different from Canadian relationships, "who are with a different person every day." Suddenly, following from the same speech, she stops talking about marriage, and exclaims, "But for us it is time to look to our own culture and to see where that has brought us! To think about illuminating ourselves, to think how we can improve and change our own culture! What has our culture done for us? I do not believe in hanging on to the past!"

In Fallah's response, himself a devout Sunni Muslim, there is a note of resignation: "But they are children, and we cannot force them. We cannot tell them to do anything they do not like. If they grow older and decide to behave differently, what can we do? Can we do anything? Once they are adults, they are eighteen, nineteen, we are released. It is up to them."

Mehrdad, a former teacher and a man who declares himself not religious, echoes a similar note, implying that parents must be able to handle the choices of their children: "

This problem that both Iranians and Afghans have, both you and us, we do not like our children too free and easy 
with their friends, to go and sleep at their friends' house and so on, yes, it is something we have to deal with."

Such generational issues are not simply religious or traditionalist matter-they can occur in any family: "Yes, it would be hurtful for me if my children got married without consulting me, or considering my opinion, but I think this is something which can happen to all parents.

The young adults seemed very considerate of their parents' sensibilities. Sabrina, a university student who comes from a family where they do not "subscribe to religious practice," says, "Actually, no, I do not like to bring my friends home, and I do not become close like that [with her Canadian friends and classmates]. What I mean is that in university we enjoy working and studying together ... My brothers also, they have their friends and so on outside. I have never seen them bring their friends home."

Arezu and Bahar, sisters attending high school, also seem skilled at defusing possible tensions and negotiating tricky family waters. Upon being asked whether they socialize with their Canadian friends to the extent of inviting them home, Bahar and her father Fallah both answer simultaneously, "Oh no," while the other family members look at each other and laugh. Bahar continues, "One of them wanted to visit me, but ..." She looks at her father and they both laugh.

Rostami-Povey also describes in detail the negotiations and concessions that Afghan parents and children make while living in Western countries, though her study group highlights instances of subterfuge practised by young adults on their parents, often resulting in their leading double lives. ${ }^{34}$ Perhaps because the interviews took place in the family setting, my respondents did not mention any such practices; however, this is not to say that there are no family conflicts.

Parvin, an Iranian woman who accompanies Farsispeaking families on official errands, confirms that there have been instances of problems about notions of family honour amongst Afghan families. However, she concurs that in general there are relatively fewer problems (compared to families of other ethnicities such as Kurds), and that Afghan girls in particular are academically successful and are flexible in adapting to the demands of both worlds. She explains, "

I think it is due to their religious affinities and traditional notions, which has positive results for the girls. The boysthey do not restrain the boys so much, and they run wild and get into all sorts of trouble-typical for teenagers. But they are careful with their girls, and so they get results."

The issue of girls' education is not a significant one in Afghan societies, and the willingness of these families to "push" the girls into academic success, as well as the declared intentions of the young girls to achieve academic success, is an important indicator of the cultural adaptation of families in Canada. Female education has long been a thorny and politically charged issue in Afghanistan, while women's human rights continue to cause controversy. ${ }^{35}$ So when a teenage Afghan girl can sit next to her parents in Halifax and say calmly, "I have no plans to marry now. I will go to university first, and find a job. I am not thinking of marriage now," this is not just a tribute to the educational attainments of second-generation immigrants. It means that these people, in becoming refugees and stepping away from their home country, are also pushing the boundaries of their home culture, which is steeped in patriarchy. They no longer conform to the norms and demands of a country where fathers, brothers, husbands, and fathers-in-law have the final and ultimate say in all decisions relating to women.

Although the parents might declare themselves accepting of the choices of their children, that does not prevent them from trying to mould those possible choices as far as they can. This is not so very different from parents all over the world. The Rezais and Razavis send all their children to regular Quran school every Saturday, while Zahra gives her children lessons on religious principles: "Occasionally, I teach them something ... I use the Internet, and I have taught them the basics. And we sometimes take them to the Bayers Road mosque. After all, I do not want them to completely forget our customs." This instruction is part of the religious lifestyle but also takes on an aspect of "remembering" and preserving their Afghan identity. Talking of the weekly Quran lessons, Maryam says, "Of course they know Quran from Iran. This is more to make sure they do not forget." And her husband, Reza concurs: "We do not want it to be said that they went to Canada and forgot everything." The message is clear: they are doing their best to bring up their children in accordance to their own values and traditions. But after the children grow up, the parents "are released."

Thus, in observing the interaction between parents and their children, and their attitude towards traditional values and norms, it can be argued that there is a sense of mutual accommodation and tolerance amongst the members of the study group. Parents agree that as children grow older, they must be free to make their own choices, whether in marriage, religious convictions, or decisions on their careers and education. Meanwhile, the young adults appear sensible to their parents' values and preferences and actively try to accommodate them. In this two-way interaction, there is a vivid demonstration of the simultaneously constraining and enabling aspects of Afghan culture. It constrains the parents from allowing their children to socialize too freely, as they see it, with their school friends. Simultaneously parents encourage or allow their children to pursue academic studies-which they clearly do not see as clashing with their 
traditional culture, and they acknowledge that ultimately the children are responsible for their own choices. And the children have a lively sense of respect for their elders that enables them to understand and appreciate their parents' mental boundaries, and so they appear willing to manage their non-familial social friendships outside the home, in a manner acceptable to their parents, but with the implicit or even explicit understanding that they are in fact free to study, to have a career, to marry when they wish, whom they wish, and to follow religious practices to the degree they wish.

\section{The Religious and the Not So Religious}

Where Tastsoglou is interested in the social aspect and the possibility that religion can ease the "social integration" of immigrants, ${ }^{36}$ Dossa concentrates on the individual: prayers and praying is an activity through which women organize their time, their space, and find solace and ease. ${ }^{37}$

Religion is an area where the personal, social, and political come together, and this is reflected in the attitude of my study participants. Of the eight families interviewed, six were visibly religious. This was as evident as in the framed Quranic verses on the walls, as in the prayer beads of the men and the full hijab of the women. All the activities and social practices-their food habits, parenting, and socializing are informed by their religious world view, though some, as we have seen, more deeply than others.

The Sunni families make a point of participating in regular communal religious gatherings, most notably the Friday prayers, which have political significance as well as a purely religious one for the individual-it is supposed to be a show of the strength and solidarity of the religious community. Reza and Fallah take their elderly father with them to the prayers. And they send their children to Quranic and Arabic classes, as discussed. They engage in these activities even though there is no requirement for them to do so, because they are part of their mental and spiritual universe, not necessarily because doing so gives them social integration, as in Tastsoglou's argument.

Religion also helps them to cope with the uncertainties and challenges of their lives on a personal level. Upon questioning Maryam on how she feels about the future of her children, she responds simply, "I pray. I am always praying for my children to be good. What else can we parents do?" Fallah, describing the frustration of relying on government handouts, says, "A man must accept what is provided to him gracefully, with thanks. In Iran, we worked and earned 200,000 a month, and we were grateful. Here, we do not work, and we are still grateful."
He uses the Arabic word shokr for gratitude, which is a word with heavy Quranic implications-to be shaker or grateful is a major characteristic of a good Muslim.

For other families, religion does not appear to be such a cornerstone of their identity. True, the women are veiled, but as the little exchange above shows, it could be little more than force of habit and custom. Asking the young couple directly about their religious convictions, Razieh's husband Bahram shrugs and says, "This is the way we have been brought up. No, we are not very religious like some others. It is not so important." Sina, another young male Afghan responds in a similar fashion. They are happy enough to attend festivities based on religious events but do not make a point of attending Friday mass prayers. For them, religion has been part of their social landscape since they were born, but now that they are in a different country where religion does not have such a prominent public place, they might find themselves thinking differently, perhaps even challenging received religious wisdom that they had been taught. For example, after remarking on the kindness he has seen from Canadian officials, Hussein states, "I cannot believe that some of our mullahs and clerics would call these people blasphemers, whereas to me they are the kindest people I have ever seen." Asked about attendance at religious gatherings, Zahra says, “

Honestly we do not have time for such things. Yes, occasionally if it is an important eid, but, no, we cannot be going to prayers and sermons regularly. We need to concentrate on other things now, our language ability and studying."

Yet she dresses with full hijab, covering her hair and body with an Iranian-style manteau and scarf. During the interview, her satin scarf regularly slips back, showing her hair in a manner unacceptable for seriously devout or observant women, and she pulls it forward, adjusting it and smoothing her hair. In these families, it appears that incorporating the symbols of religion happens more or less for the same reason they stick to preparing Afghan food-it is what they know and are comfortable with, it is more of a custom than an integral part of their identity. Zahra says as much when she describes teaching her children about religion-to repeat the quote provided above: "I have taught them the basics ... After all, I do not want them to completely forget our customs."

Two families are visibly non-religious, the Miris and the Abbasis. The women appear in casual Western-style clothes, and there are no religious ornaments to be seen. The point needs to be made that for people coming from countries where religion plays such a prominent public and statemandated role, coming forward as a visually non-religious person has social (if not political) significance. A woman appearing in a public space with her hair uncovered is 
making a declaration of her affinities, whether she likes it or not. In fact, a woman with her hair uncovered is making a statement about her husband's and family's affinities as well, not just her own. Just as scholars such as Haideh Afshar argue that assuming a religious identity can be an expression of agency and liberation for women, ${ }^{38}$ the opposite can be equally true: assuming a non-religious identity for citizens of countries where religion is woven into their constitution can be also "agentic."

Taher and Mehrdad, the fathers of the two non-religious families, both emphasize that Afghans are not all religious, and it is clear through their talk that they associate religion with ignorance and intellectual poverty. They had both been educated during the former communist regime in Afghanistan, and it is characteristic that they should not have a high opinion of religion. Sabrina, Mehrdad's daughter, uses the term free-thinker to describe herself and her family. They avoid the term religion, preferring terms such as prejudices, sensitivities, and customs. According to Mehrdad,

In Afghanistan, people still follow very primitive, provincial lives ... You can see now there is so much aid, so many international organizations, but they cannot do it [implement human rights in Afghanistan]. Historically, people prefer to continue the primitive traditions that have been handed down to them through centuries. To break free from those traditions requires sufficient stability and security, which we never had. It is very difficult. First the communists tried to bring progress to Afghanistan, but they failed. Nothing works if it is presented by force, as a sort of dogma, running counter to people's sensitivities and traditions. Slowly, gradually, perhaps some progress can be made, as people become more enlightened.

They are worldly people. The interview questions on culture and adaptation must have sounded naive to them. Says Taher, "My culture here has not changed from what I had before. I am a free person; I have lived and studied in European countries and in Russia, thirty years ago. The culture here is nothing new or shocking for me. Of course it is not the same for all families."

The categorization above is similar to that provided by Moghissi et al. and their classification of the religious tendencies of their Muslim respondents in Canada, focusing on their religious identity. They discuss four groups: the "strongly committed," "ritual practitioners," "virtual religious," and those tending to be secular, and their point is that "again, contrary to stereotypes that all people of Muslim background are very religious and their communities are similar in terms of strength of religious belief and practice, we see that the ... communities are quite different from one another, and that within each community, individuals show different degrees and kinds of religious affiliation."39

Thus, much like the other themes discussed, religion is a construct that for some individuals in my study sample was agentic: a source of solace, an expression of identity, or a familiar social practice, while for others it was constraining feature of Afghan society, the cause of suffering and "backwardness," and their own individuality was expressed in terms contrary to perceived notions of religiosity.

\section{Conclusion}

A very strong impression of knowledgeable actors, to use Giddens's term, was built up through the interviews conducted for this study. The participants displayed skill at deploying cultural practices as a form of restating and protecting their identities as "Afghans," yet retaining a very clear sense of what they do not approve of in traditional cultural practices, thus "reifying" their Afghan identity. Although clearly appreciative of the benefits of life in Canada, they betray little desire to lose their constructed "Afghan-ness" in return for their appreciation, and their gratitude to the legal and international system that brought them here does not extend to a desire to adopt a fully "Canadian" lifestyle. Indeed, they show highly individual readings of what it means to be Afghan or Canadian and seem adept at selecting or retaining what they think will work for them, out of each set of cultural practices. They do not negate or underestimate the hardships and difficulties they have been through as refugees, as people pushed by devastating wars into insecure lives, but they do not see the whole of the meaning of their existence as bound up in that past. They deeply appreciate the safety and security of their present and are eagerly anticipating an independent and self-sufficient future for themselves and their children.

In summary, I hope to have conveyed something of the individuality and heterogeneity of the Afghan people in Halifax through this discussion and analysis. More than that, I hope to have provided the feeling of people actively engaged in reconstructing their lives and imbuing it with meaning and significance through their daily practices and hopes. They build upon the structures available to them, whether these are structures brought with them as part of their cultural baggage, such as religion and food, or those that are available here, such as education and stability. By exercising their agency, they are able to make these structures uniquely theirs, reifying and challenging stereotypes of fundamentalist, conservative attitudes. Their eyes follow their children, and they make constant reference to themthe sense of future, of planning, of developing a livelihood is very present in these families. They are highly conscious of their identity and culture as Afghans. They present 
themselves publicly and purposefully as Afghan, but they do not consider this an obstacle to their settlement and integration in the society where they have found themselves. Perhaps Taher summed up their situation best of all: "It is possible for a person to have and love two homes, you know."

\section{Notes}

1. Elaheh Rostami-Povey, Afghan Women: Identity and Invasion (London: Zed Books, 2007).

2. Ibid.

3. Rhoda Margesson, CRS Report for Congress: Afghan Refugees; Current Status and Future Prospects (Washington, DC: Refugee Health Information Network, 2007), http://rhin. org/documents/CRS.report.Afghan.pdf.

4. Evangelia Tastsoglou, "Women, Gender, and Immigration: Focus on Atlantic Canada," in Immigrant Women in Atlantic Canada, ed. E. Tastsoglou and J. Peruvemba, 1-49 (Toronto: Canadian Scholars' Press / Women's Press, 2010).

5. Hannah Arendt and Jerome Kohn, Essays in Understanding, 1930-1954 (New York: Harcourt, Brace, 1994).

6. Liisa Malkki, "National Geographic: The Rooting of Peoples and the Territorialization of National Identity among Scholars and Refugees," Cultural Anthropology 7 (1992): 24-44.

7. Julia Kristeva, Étrangers à nous-mêmes (Paris: Fayard, 1988).

8. Peter Nyers, Rethinking Refugees: Beyond States of Emergency (New York: Routledge, 2006).

9. Anthony Giddens, The Constitution of Society: Outline of the Theory of Structuration (Berkeley: University of California Press, 1984).

10. Haideh Moghissi, S. Rahnema, and M. J. Goodman, Diaspora by Design: Muslims in Canada and Beyond (Toronto: University of Toronto Press, 2009).

11. Alastair Ager and Alison Strang, "Understanding Integration: A Conceptual Framework," Journal of Refugee Studies 21 (2008): 166.

12. Richard C. Nann, Uprooting and Surviving: Adaptation and Resettlement of Migrant Families and Children (Dordrecht, Holland: Reidel, 1982), xv.

13. Ibid., xii.

14. J. G. Lipson and A. Meleis, "Research with Immigrants and Refugees," in Handbook of Clinical Nursing Research, ed. A. Hinshawe, and J L. F. Shaver (Thousand Oaks, CA: Sage Publications, 1999), 88.

15. Ibid., 89.

16. T. A. P. Witmer and S. M. Culver, "Trauma and Resilience among Bosnian Refugee Families: A Critical Review of the Literature," Journal of Social Work Research and Evaluation 2 (2001): 173-88.

17. Ibid., 173.

18. J. Stack and Y. Iwasaki, "The Role of Leisure Pursuits in Adaptation Processes among Afghan Refugees Who Have
Immigrated to Winnipeg, Canada," Leisure Studies 28 (2009): 241.

19. Ibid.

20. Karin Eun-Myo Park, “The Mental Health Dimension," UN Chronicle 39 (2002): 14.

21. Parin Dossa, Politics and Poetics of Migration: Narratives of Iranian Women from the Diaspora (Toronto: Canadian Scholars' Press, 2004), 4.

22. Evangelia Tastsoglou, "Gender, Migration and Citizenship: Immigrant Women and the Politics of Belonging in the Canadian Maritimes," in Women, Migration and Citizenship: Making Local, National and Transnational Connections, ed. A. Dobrowolsky and E. Tastsoglou, 201-30 (Farnham: Ashgate Publishing, 2007).

23. Parin Dossa, "Creating Politicized Spaces: Afghan Immigrant Women's Stories of Migration and Displacement," Affilia: Journal of Women \& Social Work 23 (2008): 10-21.

24. Pauline Gardiner Barber, "Citizenship and Attachment across Borders? A Transnational and Anthropological Research Agenda," Canadian Diversity 2, no. 1 (2003): 46.

25. Ibid.

26. Robert E. Mazur, "Linking Popular Initiative and Aid Agencies: The Case of Refugees," Development and Change 18, no. 3 (1987): 454.

27. Barbara Harrell-Bond and Eftihia Voutira, "In Search of 'Invisible' Actors: Barriers to Access in Refugee Research," Journal of Refugee Studies 20, no. 2 (2007): 283.

28. Kathleen Musante DeWalt and Billie R. DeWalt, Participant Observation: A Guide for Fieldworkers (Lanham, MD: Rowman \& Littlefield, 2011).

29. Ibid., 33.

30. Renee Sylvain, "Loyalty and Treachery in the Kalahari," in Auto-Ethnographies: The Anthropology of Academic Practice, ed. A. Meneley and D. J. Young, 25-38 (Peterborough, ON: Broadview, 2005).

31. Donna Jean Young, "Writing against the Native Point of View," in Meneley and Young, Auto-Ethnographies, 214.

32. Ibid.

33. Tobi Cohen, “Honour Killings' on the Rise in Canada: Expert," Vancouver Sun, n.d., http://www.vancouversun. com/life/Honour+killings+rise+Canada+Expert/3165638/ story.html.

34. Rostami-Povey, Afghan Women.

35. Integrated Regional Information Networks, "Afghanistan: Women's Rights Trampled Despite New Law," UNHCR, 8 March 2010, http://www.unhcr.org/refworld/ docid/4b9ale83c.html.

36. Tastsoglou, "Gender, Migration and Citizenship," 220.

37. Dossa, "Creating Politicized Spaces."

38. Haideh Afshar, "Gendering the Millennium: Globalising Women" in Development and Culture, ed. Deborah Eade, Thierry G. Verhelst, and Wendy Tyndale, 131-40 (Oxford: Oxfam GB in association with World Faiths Development Dialogue, 2002). 
39. Haideh Moghissi, Saeed Rahnema, and Mark J. Goodman, Diaspora by Design: Muslims in Canada and Beyond (Toronto: University of Toronto Press, 2009), 93.

Shiva Nourpanah is a PhD candidate in the Department of Sociology and Social Anthropology at Dalhousie University. The author may be contacted at shiva.nourpanah@gmail. com.

(c) Shiva Nourpanah, 2014. This open-access work is licensed under a Creative Commons Attribution-NonCommercial 4.0 International License, which permits use, reproduction and distribution in any medium for non-commercial purposes, provided the original author(s) are credited and the original publication in Refuge: Canada's Journal on Refugees is cited. 